\title{
Isolated Intramedullary Relapse of Lung Cancer: About A Case
}

\author{
A. Bazine ${ }^{1,2,3,4^{*}}$, M. Elmarjany ${ }^{1}$, M. Benlemlih ${ }^{1}$, A. Maghous ${ }^{1}$, A. Marnouche ${ }^{1}$, M. Houmadi ${ }^{1}$, KH. Andaloussi ${ }^{1}, \mathrm{KH}$. \\ Haddadi $^{1}$, H. Sifat ${ }^{1}$, H. Mansouri ${ }^{1}$
}

\author{
${ }^{1}$ Radiotherapy department of Military Instruction Hospital Mohamed V, Rabat, Morocco \\ ${ }^{2}$ Faculty of Medicine and Pharmacy, Fez, Morocco \\ ${ }^{3}$ Sidi Mohamed Ben Abdellah University, Fez, Morocco \\ ${ }^{4}$ Mohamed V University, Rabat, Morocco
}

Intramedullary metastases (IMM) are rare. Lung cancer is the most common primary. We report in this work the case of a 59-year-old patient, previously treated with chemo-radiotherapy for locally advanced lung cancer, who presented with an isolated intramedullary relapse. Palliative radiotherapy and systemic corticosteroids were initiated with an improvement of neurological symptoms. The patient died 3 months after the diagnosis of IMM. Through this work, we underline the singularity of the isolated character of the reported relapse and the importance of an early diagnosis of these lesions, often associated with a poor prognosis.

Keywords: Intramedullary metastases, isolated relapse, lung cancer.

Copyright @ 2020: This is an open-access article distributed under the terms of the Creative Commons Attribution license which permits unrestricted use, distribution, and reproduction in any medium for non-commercial use (NonCommercial, or CC-BY-NC) provided the original author and source are credited.

\section{INTRODUCTION}

Development of IMMs is still a rare event during course of cancer. However, it is increasing due to more effective therapies which prolong overall survival [1]. Their occurrence is generally consistent in a context of multi-metastatic disease [2]. To our knowledge, isolated character of IMM has never been reported in literature. IMMs is associated with a poor prognosis and treatment is generally palliative aimed at improving neurological symptoms [3].

We report in this work the case of a 59-yearold man, previously treated with chemo-radiotherapy for locally advanced lung cancer, who presented with an isolated intramedullary relapse. Palliative radiotherapy and systemic corticosteroids were initiated with an improvement of neurological symptoms. The patient died 3 months after the diagnosis of IMM.

We underline, through this case, originality of the isolated character of this relapse and insist on the importance of exploration of spinal cord during extension assessments, in order to diagnose early IMMs, because ablative treatments are associated with better outcomes.

\section{CASE REPORT}

This is a 59-year-old man, followed since October 2017 for squamous cell carcinoma of the right lung; initially classified as IIIB. The patient received concomitant chemo-radiotherapy (three-dimensional conformal radiotherapy: 66 Gray in 33 fractions; chemotherapy: 03 cycles of Carboplatin AUC5 on D1, Paclitaxel $175 \mathrm{mg} / \mathrm{m}^{2}$ on D1, every 21 days).

The patient remained in good locoregional and distant control until March 2019 when the patient presented with progressively worsening paraparesis, associated with paresthesias of both lower limbs, without respiratory or bone signs that could be related to progression of lung cancer.

Neurological examination revealed a pyramidal syndrome with decreased of vibratory sensitivity. Remainder of somatic examination was unremarkable.

Spinal cord magnetic resonance imaging (MRI) showed the presence of an intramedullary process at level of medullary cone, measuring $8 \mathrm{~mm}$ axially and extended over $28 \mathrm{~mm}$, which may correspond either to an ependymoma, an astrocytoma or a secondary lesion (Figure $1 \& 2$ ). 


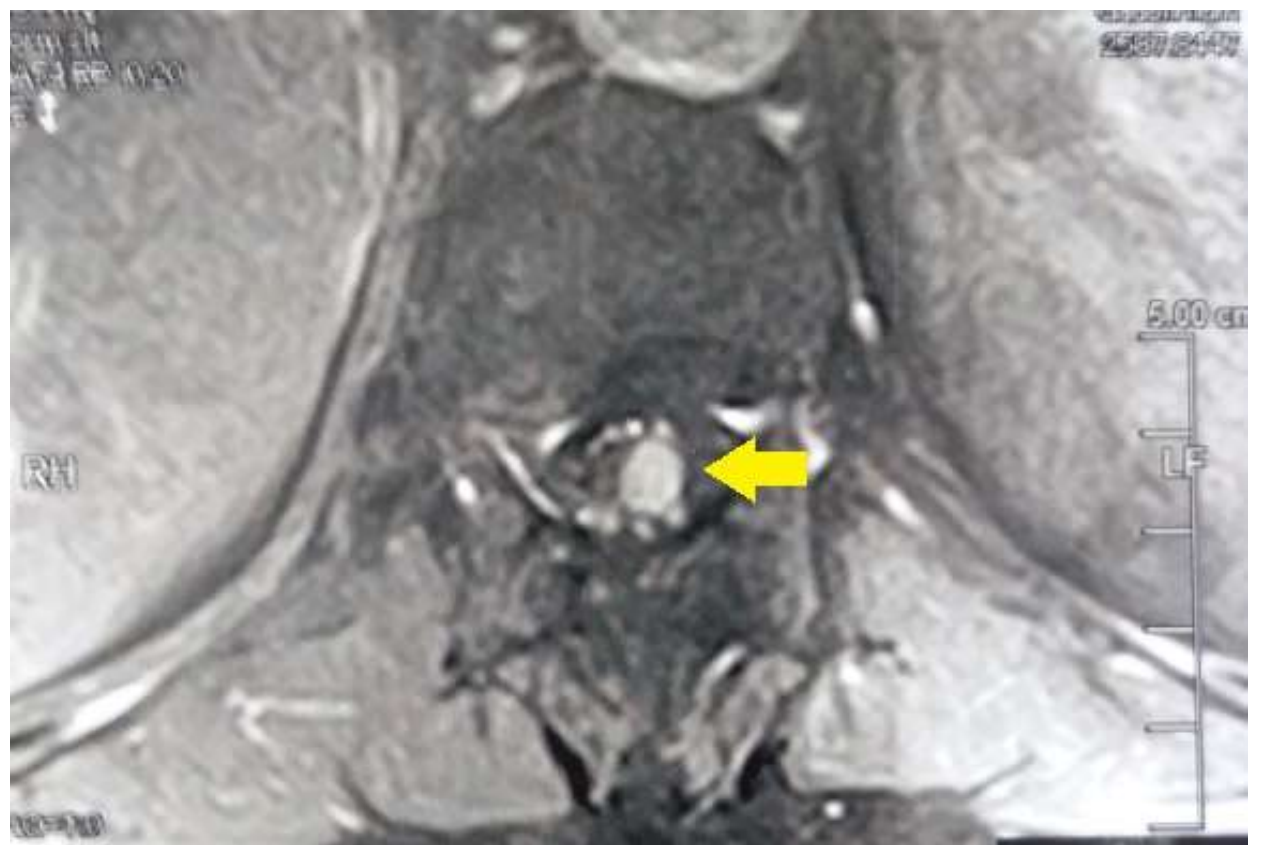

Fig-1: Axial MRI section showing an intramedullary process at level of medullary cone, in hyper signal T1 with injection of Gadolinium (yellow arrow)

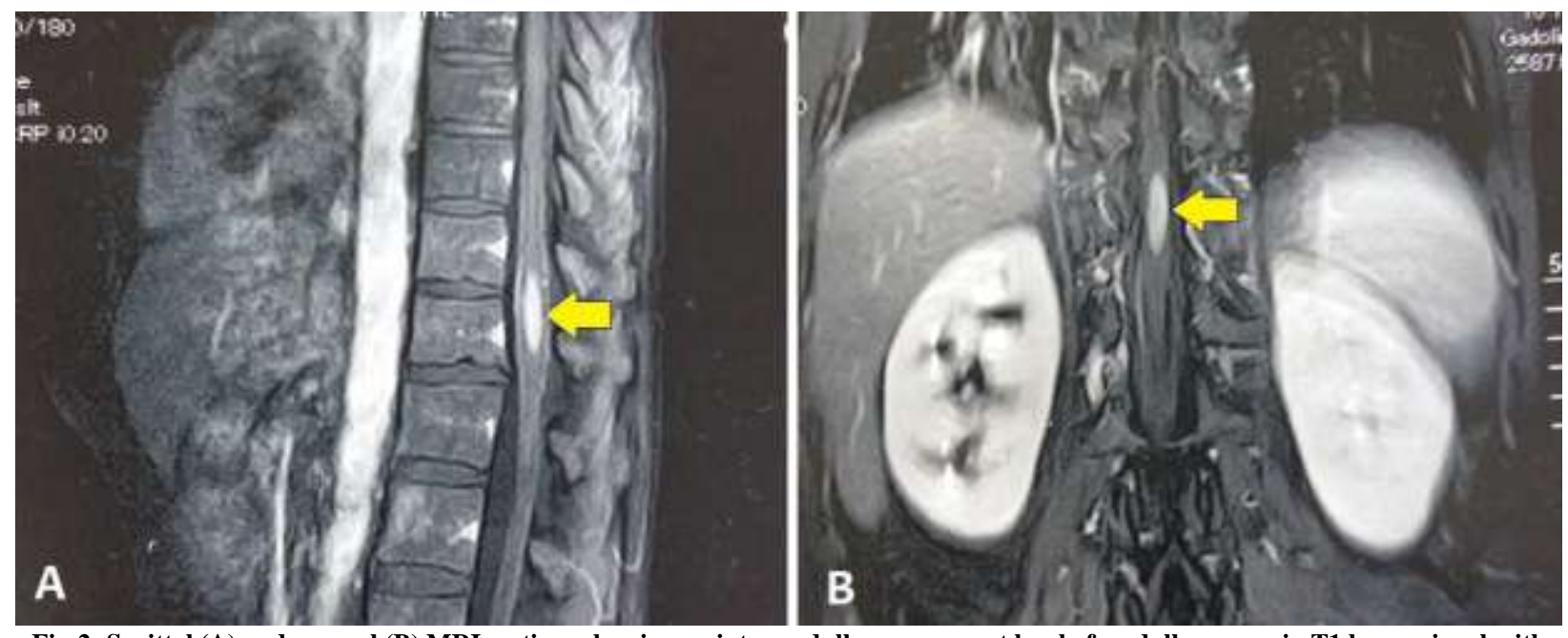

Fig-2: Sagittal (A) and coronal (B) MRI sections showing an intramedullary process at level of medullary cone in T1 hyper signal with injection of Gadolinium (yellow arrow)

A positron emission tomography coupled to computed tomography (PET-CT) was requested to complete extension assessment, and demonstrated an intense intramedullary pathological hyper-metabolism with a maximal standardized uptake value (SUV) estimated at 23, extended from D11 to L1, more suggestive of a secondary location than a glioma, since binding is very weak in the latter histological type (Figure-3). Examination also showed a right pulmonary hyper-metabolism, corresponding to the primary tumor, associated with a mediatisnal lymph node hypermetabolism. However, no other secondary hepatic, pulmonary, bone or distant lymph node lesions were found. 


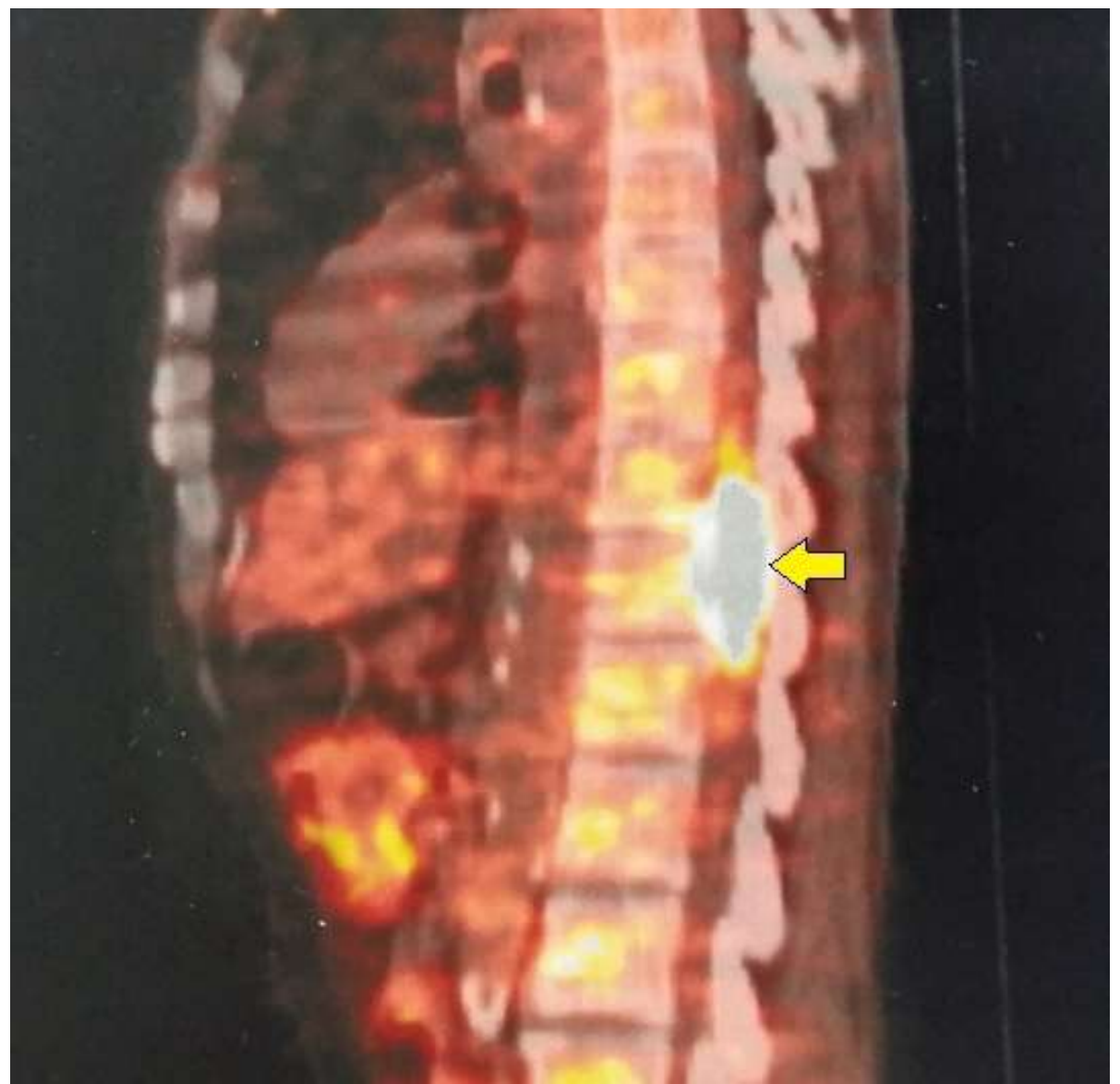

Fig-3: Sagittal PET-CT fusion image showing an intense intramedullary pathological hyper metabolism (yellow arrow)

\section{Brain MRI did not show any secondary brain damage}

The patient received systemic corticosteroids based on methyl-prednisolone at a dose of $120 \mathrm{mg}$, twice a day and palliative radiotherapy on the IMM, at a dose of 30 Gray, at a rate of 3 Gray per fraction, 5 fractions per week for two weeks. Clinical course was satisfactory with improvement in paraparesis and paresthesias of lower limbs.

Search for oncogenic addictions came back negative and the patient was put on chemotherapy (Docetaxel $80 \mathrm{mg} / \mathrm{m}^{2}$ every 3 weeks). After 3 cycles of chemotherapy, 3 months after the diagnosis of the IMM, the patient died due to deterioration in his general condition.

\section{DISCUSSION}

IMMs are extremely rare [1], particularly before implantation of MRI in assessment of cancer extension and before various advances made in treatment of cancer, leading to prolonged survival of patients. This has resulted in an increase in number of published cases [2].

Epidemiologically, IMMs more often affects elderly patients and there is no gender predominance [3]. They generally occur during course of cancer but can be indicative of cancer in 18.74 to $25 \%$ of cases of
IMMs, and are rarely isolated, often associated with other metastases, especially brain [3], which represents the singularity of the case reported in this work, where intramedullary metastatic relapse is isolated without other metastatic sites elsewhere, and which is synchronous with a tumor revival at level of already known primary lung cancer. Time to onset of IMMs after cancer diagnosis can be up to 10 years [3], in our case this time is of the order of 18 months.

As previously reported [1-4], lung cancer is the primary source of IMM, in particular squamous cell carcinoma, followed by breast cancer. This can be explained by the high prevalence of these two cancers and by improvement in therapeutic arsenal leading to a prolongation of survival letting IMMs appear.

03 routes of dissemination may explain occurrence of IMMs [5]; the most frequent is hematogenous route through arterial or venous vascular system; leptomeningeal seeding using cerebrospinal fluid, from brain metastases; and finally direct invasion from metastases to adjacent structures, in addition to vertebral metastases first invading the leptomeningeal tunics before reaching medullary parenchyma. In our case, the fact that intramedullary metastatic relapse is isolated; the most probable mode of dissemination is hematogenous route. 
Topographically, it appears that thoracic segment is the most frequently affected, followed by cervical segment [6]. In our case, the lesion occurred at level of lumbar segment which represents terminal part of spinal cord.

Semiologically, IMMs generally causes edema with distortion and compression of the parenchyma of spinal cord, causing pain and sensory disturbances, followed by weakness, then sphincter dysfunction. However, they are rarely asymptomatic. Rapid deterioration of neurological symptoms within less than a month distinguishes IMMs from primary intramedullary tumors whose symptoms tend to progress more slowly [7].

Cerebrospinal MRI is the gold standard for looking for IMMs. The lesions take on contrast in $98 \%$ of cases, are multiple in $20 \%$ of cases and are associated with extensive edema extending over more than 3 vertebral segments. Search of associated bone metastases is imperative and are frequents. Differential diagnosis is mainly that of a primary tumor of central nervous system [8]. Two semiological signs make it possible to point to a metastatic origin; 1) The "ring sign" which is defined by presence of a complete or incomplete annular enhancement outside of central contrast enhancement; 2) The "flame sign" which corresponds to an ill-defined enhancement at upper or lower pole of lesion, with flame appearance [6].

PET-CT is requested as part of lung cancer extension assessment and makes it possible to map various metastatic lesions. Its place in identification and characterization of IMMs is still poorly defined. It is described that sensitivity of PET-CT is reduced in cases of lesions with little clinical impact, small size or associated with minimal peri-lesional edema [9]. PETCT can be considered to differentiate IMMs from primary intramedullary tumors, characterized by a lower SUV [10]. It retains a place in case of contraindications to MRI or unable to tolerate intravenous injection of Gadolinium [9].

Treatment is generally palliative [11]. Normofractionated external beam radiation therapy provides clinical improvement in radiosensitive tumors such as lung cancer, unlike radiation resistant tumors such as kidney cancer or melanoma [12]. Stereotaxic radiotherapy is promising, and only concerns small lesions with oligo-metastatic disease [13].

For a long time, surgery had no role in management of IMMs. With development of neuronavigation and microsurgical techniques, radical resection may be indicated in some highly selected patients (limited lesion, satisfactory general condition), and may result in benefit in cancer control and neurological improvement [14].
Due to existence of a blood-spinal barrier, chemotherapy has little effect on the treatment of IMMs. It is reserved for chemo-sensitive tumors, such as small cell lung cancer, and as an adjunct to radiotherapy or surgery [15].

For patients with symptoms of rapidly onset spinal cord compression, corticosteroids can rapidly relieve pain and delay neurological deterioration by reducing local tissue edema and promoting normal blood-spinal barrier, but without impacting overall survival [14].

In terms of prognosis, the presence of IMMs is a factor of poor prognosis with a median survival varying between 3.9 and 5 months [16]. Our patient died 3 months after the diagnosis of IMM. Pulmonary or mammary origin of primary cancer is associated with a poor prognosis [4]. Multiple locations and lack of treatment are also poor prognostic factors that influence overall survival [4].

\section{CONCLUSION}

Occurrence of IMMs in course of cancer is an extremely rare event, especially since it is an isolated relapse. However, improvement of various anticancer therapies has made it possible to prolong survival and therefore increase incidence of IMMs, increasingly reported in literature. This requires special attention when interpreting various radiological or metabolic examinations carried out as part of extension workup, in order to detect and diagnose small intramedullary lesions early on, and which are associated with a much better prognosis.

\section{REFERENCES}

1. Rades D, Schiff D. Epidural and intramedullary spinal metastasis: clinical features and role of fractionated radiotherapy. Handb Clin Neurol. 2018; 149:227-238.

2. Payer S, Mende KC, Westphal M, Eicker SO. Intramedullary spinal cord metastases: an increasingly common diagnosis. Neurosurgical focus. 2015 Aug 1;39(2):E15.

3. Lv J, Liu B, Quan X, Li C, Dong L and Liu M. Intramedullary spinal cord metastasis in malignancies: an institutional analysis and review. Onco Targets Ther. 2019; 12: 4741-4753.

4. Diehn FE, Rykken JB, Wald JT, Wood CP, Eckel LJ, Hunt CH, Schwartz KM, Lingineni RK, Carter RE, Kaufmann TJ. Intramedullary spinal cord metastases: prognostic value of MRI and clinical features from a 13-year institutional case series. American Journal of Neuroradiology. 2015 Mar 1;36(3):587-93.

5. Hrabalek L. Intramedullary spinal cord metastases: review of the literature. Biomed Pap Med Fac Univ Palacky Olomouc Czech Repub. 2010; 154(2):117-122. 
6. Rykken JB, Diehn FE, Hunt CH, Schwartz KM, Eckel LJ, Wood CP, Kaufmann TJ, Lingineni RK, Carter RE, Wald JT. Intramedullary spinal cord metastases: MRI and relevant clinical features from a 13-year institutional case series. American Journal of Neuroradiology. 2013 Oct 1;34(10):2043-9.

7. Ding D, Fullard M, Jarrell HS, Jones DE. Intramedullary spinal cord metastasis from salivary ductal carcinoma of the parotid gland mimicking transverse myelitis in a patient with radiologically isolated syndrome. J Neurol Sci. 2014 Jan 15; 336(1-2):265-8.

8. Cosnard G, Duprez T, Grandin C, et Hernalsteen D. Moelle épinière tumorale et pseudo-tumorale. J Radiol. 2010 Sep; 91:988-97.

9. Mostardi PM, Diehn FE, Rykken JB, Eckel LJ, Schwartz KM, Kaufmann TJ, Wood CP, Wald JT, Hunt $\mathrm{CH}$. Intramedullary spinal cord metastases: visibility on PET and correlation with MRI features. Am J Neuroradiol. 2014 Jan; 35(1):196201.

10. Tomura N, Ito $\mathrm{Y}$, Matsuoka H, Saginoya $\mathrm{T}$, Numazawa SI, Mizuno Y, Watanabe K. PET findings of intramedullary tumors of the spinal cord using [18F] FDG and [11C] methionine. American Journal of Neuroradiology. 2013 Jun 1;34(6):1278-83.
11. Lee SS, Kim MK, Sym SJ, Kim SW, Kim WK, Kim SB, Ahn JH. Intramedullary spinal cord metastases: a single-institution experience. Journal of Neuro-oncology. 2007; 84:85-89.

12. Hashii H, Mizumoto M, Kanemoto A, et al. Radiotherapy for patients with symptomatic intramedullary spinal cord metastasis. J Radiat Res. 2011; 52(5):641-645.

13. Parikh S, Heron DE. Fractionated radiosurgical management of intramedullary spinal cord metastasis: A case report and review of the literature. Clin Neurol Neurosurg. 2009; 111(10):858-861.

14. Kalita O. Current insights into surgery for intramedullary spinal cord metastases: a literature review. Int J Surg Oncol. 2011; 2011:989506.

15. Kalayci M, Cagavi F, Gul S, Yenidunya S, Acikgoz B. Intramedullary spinal cord metastases: diagnosis and treatment - an illustrated review. Acta Neurochir (Wien). 2004; 146(12):13471354.

16. Conill C, Marruecos J, Verger E, Berenguer J, Lomena F, Domingo-Domenech J, Grau JJ, Casas F. Clinical outcome in patients with intramedullary spinal cord metastases from lung cancer. Clinical \& Translational Oncology. 2007; 9:172-176. 